
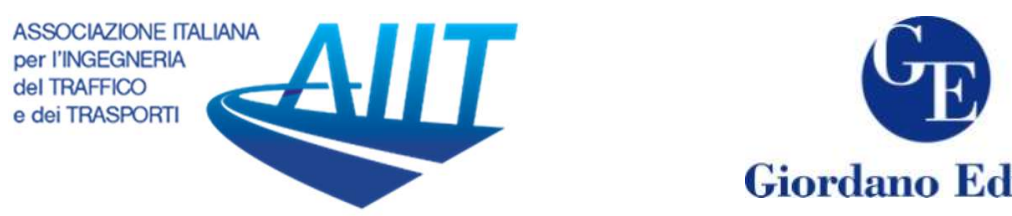

Giordano Editore

\title{
Evaluation model for local transit effectiveness to support the service design in weak demand areas
}

\author{
Umberto Petruccelli ${ }^{1}$
}

\author{
${ }^{1}$ Universita' della Basilicata - Potenza (Italy) - umberto.petruccelli@unibas.it
}

\begin{abstract}
In a public transport network, an integration between lines generally involves, on one hand, the reduction in the number of direct links, which forces users to perform more vehicle switches, and on the other hand, the possibility of supplying a greater number of rides with the same mileage. Thus, the conversion of a direct link scheme to a feeder-trunk one to improve transit service efficiency in weak demand areas produces both negative and positive effects on accessibility.

This paper deals with the built of a model able to estimate an equivalent travel time, taking into account the discomfort caused to users by the vehicle switch and the benefit arising from the greater availability of public transit rides. To validate this model and highlight benefits and limitations resulting from feedertrunk supply schemes an application to a case study was developed.
\end{abstract}

Keywords: local transit; transport supply schemes; vehicle switch cost; low-density areas accessibility

\section{Introduction}

In public transit services, feeder-trunk schemes compared with direct-link ones (also called point-to-point) usually allow saving of mileage with the same number of daily rides or increasing the number of supplied rides while keeping the total mileage unchanged. This phenomenon, well known to the planners of public transport networks, is the logical consequence of the rides overlapping along the route sections common to several lines. The overlapping paths are necessary in direct lines and conversely, avoided in integrated ones. A comparison between the two schemes in figures 1 and 2 intuitively proves the above stated. 


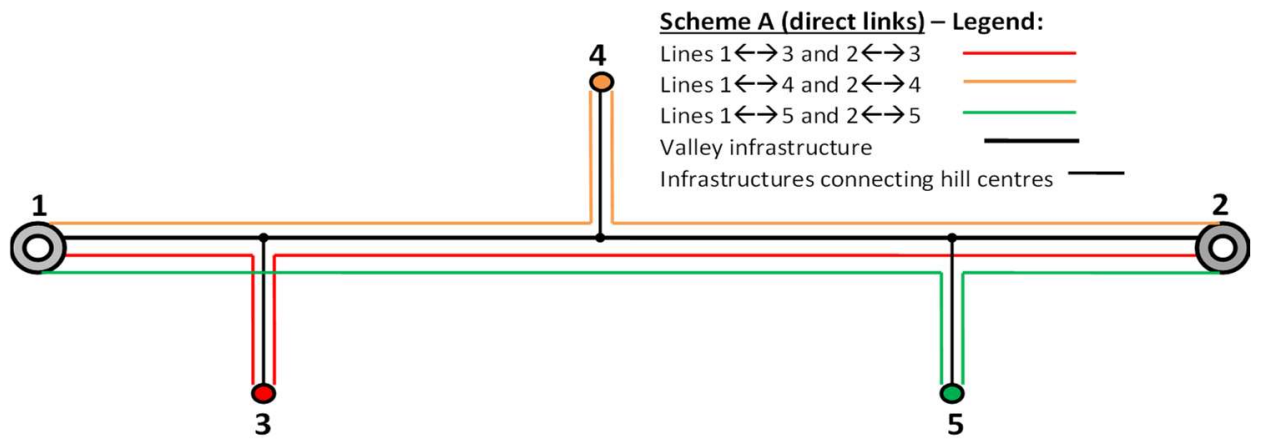

Figure 1 - Scheme A (direct links)

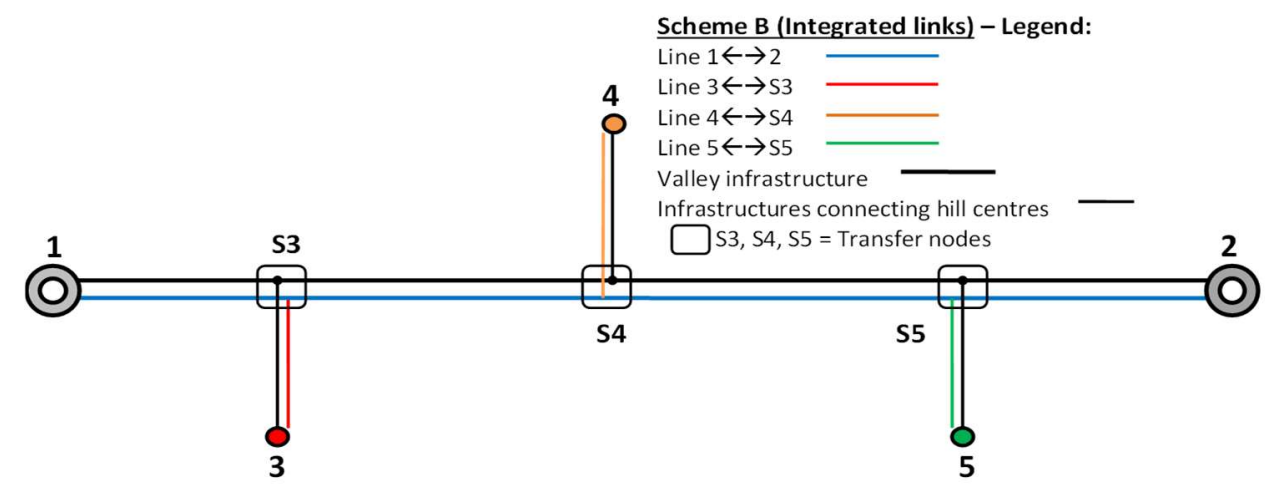

Figure 2 - Scheme B (integrated links)

Scheme A, which is characterized by direct lines (point-to-point links), in contrast to scheme B with integrated lines (feeder-trunk links), requires, in principle, a major mileage for the same number of supplied links. However, it is worth noting that scheme B, notwithstanding the advantages, requires all travellers, except those who move between the major centres 1 and 2, to change vehicle at least once in going from a secondary centre $(3,4,5)$ to a main one ( 1 or 2$)$ or vice versa, and even two times in moving from a secondary centre to another.

Clearly, the possibility of adopting scheme B depends on the capacity available along the valley line, which should be verified. In effect, the removal of the transit rides overlapping along the route sections common to several lines reduces consequently, along these sections, the supplied capacity which may therefore not be enough. However, at least in the off-peak hour and in low-density settlements areas characterized by low transport demand, the decrease in capacity is usually not a problem.

Thus, the change in service from type A (direct links or point-to-point) to type B (integrated links or feeder-trunk), which forces most users to have at least one transfer, is accompanied, at the same overall mileage, by the increase in the number of rides owing to the re-use of the saved mileages (as moreover confirmed by some studies e.g. Gschwender et al., 2016, Sivakumaran et al. 2012). The higher number of rides compensates for the sacrifice imposed on the users by the transfers; the integrated scheme provides a further appreciable advantage, that is, as can be observed from the example above, the strengthening of connections between the smaller centres. 
Different schemes for public transport service, with the same total mileages and thus, in principle, with the same cost of production, can differ according to the number of direct and integrated links between the points of the territory to be served. The fewer the direct links, the more the transfers required for users; however, in this case, there may be some more supplied rides.

The accessibility produced by a public transport service cannot be assessed only by the travel time but it needs a function that takes into account, with an appropriate weight, each of the service attributes that affect the generalized cost suffered by the user as well as the lost time by the latter at destination as a consequence of the non-perfect correspondence of the time of the ride used, with the purposes of the journey. The weight or coefficient to be associated with each attribute represents the trade-off between the characteristics, that is the user's willingness to exchange a quantity of each one with a different quantity of another one.

The number of transfers imposed on travellers and the number of offered rides have an opposite effect on the generalized cost of transport. In fact, the first raises the generalized cost due to an increase in travel time and a decrease in comfort; conversely, the addition in the number of the rides decreases the generalized cost, thanks to a reduction in the total travel time resulting from an abatement in waiting times, in particular those for the return ride. Therefore, the level of integration of the lines, through which the supplied links are made, affects the accessibility given to the served territory.

Enhancing accessibility is the main objective to be achieved through public transport supply, especially in areas with low settlement density; therefore, the effectiveness of the service can be assessed through a measure of accessibility produced by it.

Naturally, if we do not take into account the possibility of compensating by a greater number of supplied rides the inconvenience imposed by the transfer, the validity of the feeder-trunk schemes for the user is limited to scenarios where the demand is such as to keep low the number of users forced to transfer (Jara-Díaz et al., 2012). Likewise, the service feeder-trunk shows great potential if, when passing from a direct-link scheme to a feeder trunk one, the economized mileage is returned to the services in terms of new rides in order to compensate for the deterioration in service quality and accessibility caused by transfers.

For what has been said, the replacement of direct links with integrated ones without having negative repercussions on accessibility requires knowing how burdensome the vehicle switch in terms of not only lengthening the travel time but also of the inconvenience and loss of comfort is for the user. At the same time, it requires knowing how advantageous it is to have a greater number of rides in the day that bring the transport supply closer to the departure time requested from trips without precise features. Only if we know the trade-off between the number of transfers with well-defined characteristics (equipment of transfer points and average transfer time) and the number of additional rides we can evaluate the change in accessibility produced by the shift from a direct-link scheme to a feeder-trunk one.

The problem mainly concerns, even if not exclusively, the areas and traffic routes with weak and widespread demand where direct links achieve low load factors and then they need to be converted into feeder-trunk links.

This work provides a solution to the problem of the evaluation of the accessibility that different schemes of public transit (also characterized by the same mileage and the same connection matrix) can produce on the served area. These transit schemes, which differ from each other in the number of direct and integrated links, lead to a certain number of 
imposed transfers and supplied rides, depending on how much each scheme approaches to the opposite direct-link or feeder-trunk types. Among the feasible supply schemes, we have to prefer the one that ensures maximum accessibility particularly in the areas with weak and widespread demand which generally do not have capacity problems. To evaluate the accessibility allowed by each scheme, we developed a tool taking into account only the discomfort and the time-delay resulting from transfers, as well as the number of supplied rides affecting the waiting time. The calibration of the model has been made by values taken from the literature related to situations similar in some respects.

The flowchart in figure 3 is the logical procedure followed in this work.

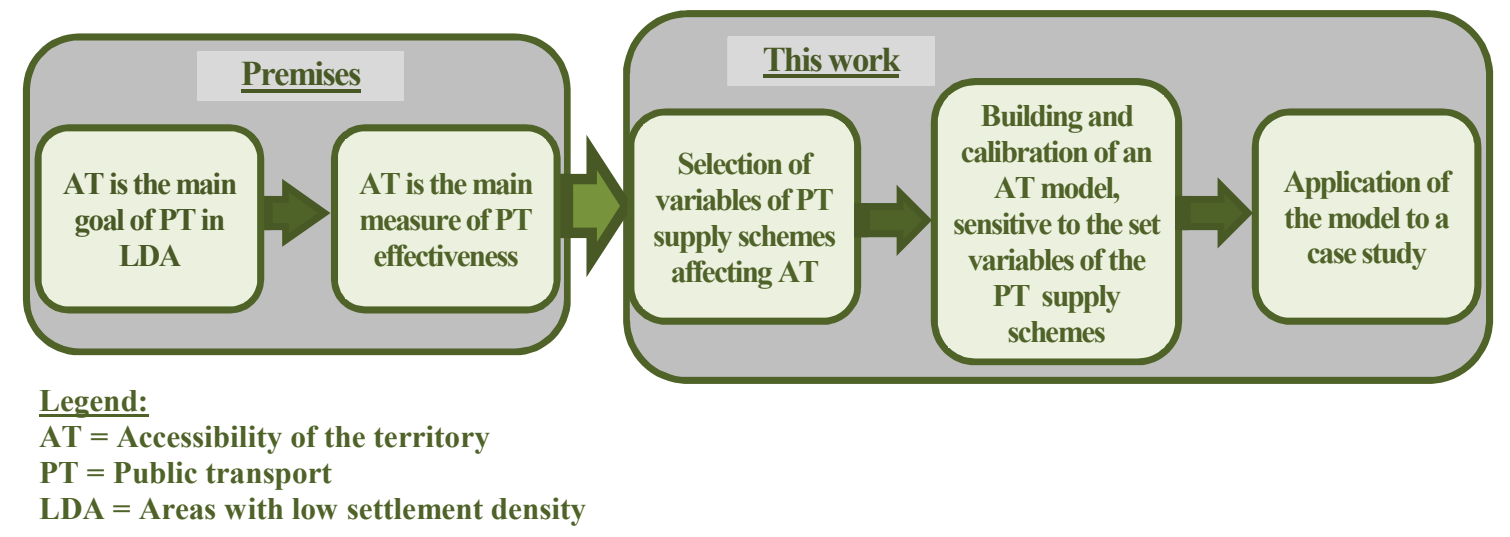

Figure 3: Logical procedure followed in this work

The issue dealt with in this work is not explicitly covered in any research published in the international literature. Nor it is possible to find scientific works that deal with the effects, on accessibility, of the number of transfers imposed and the number of rides supplied to users. This work therefore fills the gap, found in current knowledge, about the evaluation of accessibility produced by a public transport scheme, taking into account the number of transfers imposed and the number of rides supplied to users by the service.

The following is a bibliographic analysis (section 2) regarding the evaluation of accessibility as a variation of some features of the network scheme and the impact that a transfer and waiting time at a destination have on the accessibility produced by the transport system. The proposed model is built and calibrated as described in section 3 (Methodology). In section 4, we present its application to a real case in which a transport supply organized according to scheme A (direct links) is redesigned according to scheme B (integrated links) without the user perceiving a decrease in its potential for travel and that is without a reduction of accessibility. The conclusions on the validity and usefulness of the model are presented in section 5 .

\section{Literature review}

The design of a public transport service is a complex issue, usually divided into several phases, each oriented to define specific features of the project, which are combined to build a suitable supply (see for example Guihaire and Hao, 2008). The present work does not address the topic of the design of the overall transit service but aims to provide a tool to evaluate the effects on accessibility resulting from the operation of different supply schemes with particular reference to the direct connection scheme (point to point) and the integrated connection one (feeder-trunk). Therefore, we have first of all identified a measure of accessibility that is sensitive to some characteristics of the public transport. 
At present, a single and precise definition of accessibility does not exist because this feature has many aspects, each closely related to the requested use and to the context in which we operate. However, aspects common to all the accessibility definitions could be summarized in terms of the ease of reaching each activity on the territory from a separate location, using a given transport system (Dalvi and Martin, 1976). The research produced many indicators expressing the concept of accessibility and measuring its main aspects. Among the accessibility indicators, it is possible to distinguish those based only on physical measures from those that also refer to the settlement characteristics of the territory.

Accessibility in terms of physical distance is expressed by a distance indicator, which measures it in terms of travel space or time from origin to destination. More often, we use as indicator, the generalized cost that is more representative of the travel burdens. Accessibility as a direct function of the average distance, time, or generalized cost, unlike the majority of the other parameters, expresses a value as lower as the greater the ease to reach the site. The indicator is often used in the theory of graphs with other topological measurements such as the number of network nodes or links (Cattan, 1992), as well as in geographic research and network analysis.

The accessibility as a physical measure, expressed as a function of the generalized cost of travel, is the most suitable way of evaluating and comparing the quality of connection realized by different public transport schemes serving the same territory.

On accessibility related to public transport, the attention of scholars has been directed to aspects different from those discussed in the present work. For example, Murray and $\mathrm{Wu}$ (2003) tried to establish the optimum between increased stops and consequent decrease in commercial speed using a function for measuring the accessibility of the served area, which takes into account the number of stops and the commercial speed. Vasconcelos and Farias (2012) instead studied the influence, on accessibility, of the overall distance to be overcome which represents an impedance to possible trip.

Complying with the formalization of the problem developed in section $z 1$, the accessibility model proposed in the following is based on a measure of the generalized cost of travel, limited only to the travel time, but considering its main parts and associating to them suitable weights that are calibrated on the importance, which is ascribed to them by the transport users. The importance of the different parts of travel time is obtained from some studies mentioned below, which developed modal choice or perceived quality models.

An integrated transport system has great potential as it makes possible a considerable number of links avoiding overlaps of services. There are five main requirements for an integrated system (Chowdhury and Ceder, 2013) and all must be satisfied in order to consider a transport system as properly planned. They are network integration, integrated transfer time, integrated physical connection for transfer, information integration and fare and ticket integration.

A contribution to the estimate of the generalized cost for the users of public transport has been given by some scholars who, although with purposes other than the present research, have dealt with the evaluation of the discomfort endured by users during the waiting or in the transfer (vehicle switch).

The transfer from one vehicle to another influences the perceived quality and usefulness of the service to varying degrees depending on the type of user. Chowdhury et al. (2018) found that for occasional users who are forced to transfer, the most important attribute is 
'fare and ticketing integration' while for habitual ones, all attributes have a considerable weight, particularly 'integrated time transfers' or transfer time.

It is known that public transport users are very sensitive to the time spent outside the vehicle and, in particular, to the time spent waiting at stops. In general, the scientific community has always considered that the waiting time and the time spent walking are more burdensome as the one spent on board. There are many studies that try to establish, with precision, what is actually the relationship between waiting time and time on board. In the US, a value ranging from 2.0 to 4.5 was found; in particular, it is 2.58 in Houston, 3.41 in Chicago (Parsons Brinckerhoff Quade and Douglas Inc., 1998, 1999), and 2.13 in Cleveland (Barton-Ashman Associates, 1993). These values do not differ significantly from those found in Europe (Wardman, 2013).

Fan et al. (2016), in a research on the perception of time at stops and at stations, provided, moreover, the most frequently proposed values for the ratio between perceived waiting time and in-vehicle time (IVT), showing a concentration around 2.5.

The change of vehicle imposes an additional cost to the passengers as well as an increase in the travel time required. Generally, the models translate this mathematically with a penalty owing to the transfer. Douglas and Jones (2013) interviewed, through stated preference (SP) questionnaires, 900 passengers of all transport modes thus obtaining, for $50 \%$ of the observations, a transfer penalty (in IVT minutes) between 5 and 9. Douglas and Jones also reported, for bus users, transfer penalty values determined in Australia in a range from 5 to $8.5 \mathrm{~min}$, although the value of $5 \mathrm{~min}$ is more reliable because it was obtained from a greater number of observations.

Iseki and Taylor (2009), highlighting in literature the general lack of a clear conceptual framework about the effect of waiting and transfers on the users of public transport, tried quantify the drawback resulting from these operations, inside of the generalized travel cost. To this end, they developed an analysis of the values attributed in literature to the waiting and the transfer time, with the ultimate goal of supporting the evaluation of improvements to be made at the transfer stops / stations.

In addition, the work of Wardman (2001) is aimed at analysing transfer operations. He carried out a specific study, based on SP questionnaires, concerning the transfer penalty and the time spent waiting or walking. The study established that for users of road public transit, the transfer drawback ranges from $3.6 \mathrm{~min}$ to $4.5 \mathrm{~min}$ if the connection is guaranteed. Moreover, it also determined that the waiting and walking time are, respectively, 1.2 and 1.6 times the travel time.

A strong variability of the weight attributed by the user to the time spent outside the vehicle (walking or waiting) compared to the one spent on the vehicle emerges from the literature. This weight is affected by many factors attributable to the characteristics of transport service, user and the context in which this time is spent.

It is also noted that, if the studies on the weight attributed by the user to the time outside the vehicle are numerous with reference to the urban context, they are very scarce in the extra-urban context.

In summary it can be stated that a precise estimate of the weight of the time spent outside the vehicle for the user would require field investigations, carried out on very large samples, able to detect the value attributed in a specific combination of the characteristics of the service, of the user and context. However, the values thus derived would have a decidedly limited scope to the specific context to which they refer, with very little possibility of generalization. On the contrary, an estimate based on values taken from the literature, while being less precise, guarantees values applicable to broader areas 
on the condition of selecting bibliographic sources based on the similarity between the contexts considered therein and the one studied. This approach was followed in this study.

\section{Methodology}

Accessibility, measured as an inverse function of the generalized cost, can be expressed as

Being:

$$
\mathrm{A}=\mathrm{K} / \mathrm{Cg}
$$

$\mathrm{A}=$ measure of accessibility

$\mathrm{K}=$ constant $\neq 0$

$\mathrm{Cg}=$ generalized cost perceived by the user of the transport system

The generalized cost of transport or cost perceived by the user is expressed by

$$
\mathrm{Cg}=\mathrm{M}+\mathrm{wT}_{\mathrm{T}} \cdot \mathrm{T}+\mathrm{wR}_{\mathrm{R}} \cdot \mathrm{R}+\mathrm{wS}_{\mathrm{S}} \cdot \mathrm{S}
$$

Where:

$\mathrm{M}=$ monetary cost associated with the trip;

$\mathrm{T}, \mathrm{R}, \mathrm{S}=$ (respectively) the total travel time, the risk and the stress borne to move; $\mathrm{w}_{\mathrm{T}}, \mathrm{w}_{\mathrm{R}}, \mathrm{w}_{\mathrm{S}}=$ the monetary value of a unit quantity of time, risk and stress, respectively.

As known, in the transport generalized cost, the item "risk" depicts the user's feeling of uncertainty, resulting from the perception of insufficient safety or security or of a possible delay of the ride on the scheduled time, as well as of anything else that could reduce the usefulness of the trip. "Stress", on the other hand, can be associated with the lack of comfort in the various phases of the door-to-door movement, which causes the traveller to feel tension, fatigue, boredom or discomfort. Risk and stress are measurable through a dimensionless score and evidently they are subjectively evaluated.

In turn, the total travel time $\mathrm{T}$ in (2) can disappear through the relationship

$$
\mathrm{T}=\mathrm{T}_{\mathrm{V}}+\mathrm{T}_{\mathrm{A}}+\mathrm{T}_{\mathrm{T}}+\mathrm{T}_{\mathrm{I}}
$$

With $\mathrm{T}_{\mathrm{V}}, \mathrm{T}_{\mathrm{A}}, \mathrm{T}_{\mathrm{T}}, \mathrm{T}_{\mathrm{I}}$ total travel time components, which can be identified, respectively, in travel time, waiting time, any transfer time from one vehicle to another and time necessary to reach the departure stop from the origin of the journey and to reach the destination from the arrival stop.

We built a tool to measure accessibility produced by different road public transit supplies. This tool evaluates an equivalent travel time representative of the generalized cost that is an inverse function of the accessibility according to (1). By this tool, we can compare different public transit supplies that are realized with the same transport system on the same routes and stops but differ from each other because get more closer to a direct-link scheme or a feeder-trunk one. Therefore, the terms that can vary from a supply scheme to another, in the formulation of the generalized cost (2), are the total travel time $\mathrm{T}$, the stress $\mathrm{S}$ and also the risk $\mathrm{R}$ for the only part related to possible delays at the transfer points. Moreover, the possible variation of $\mathrm{R}$ and $\mathrm{S}$ in the different schemes compared is, however, attributable only to the different number of imposed transfers as well as the difficulty, punctuality and reliability with which they occur. Therefore both R and S, as they vary from each scheme to another only due to transfers, can be neglected within the generalized cost (2) if an appropriate weight is attributed to the "transfer time" component contained in the total travel time (3). On the other hand, since the components of the total time expressed by (3) have different importance for the user, it is appropriate to attribute to each of them a weight representative of how much each is considered burdensome by the user compared to the on-vehicle time $T_{V}$. Thus, from (3) it is possible to deduce the equivalent total travel time, i.e. the total time as perceived by the user 


$$
\mathrm{T}_{\mathrm{E}}=\mathrm{T}_{\mathrm{V}}+\mathrm{K}_{\mathrm{A}} \cdot \mathrm{T}_{\mathrm{A}}+\mathrm{K}_{\mathrm{T}} \cdot \mathrm{T}_{\mathrm{T}}+\mathrm{K}_{\mathrm{I}} \cdot \mathrm{T}_{\mathrm{I}}
$$

For what has been said, the weight $\mathrm{K}_{\mathrm{T}}$ associated to the transfer time is representative of the stress or discomfort caused by the transfer. The greater number of offered rides can reduce waiting times at departure stops, especially for the return journey.

Anyhow, the greater number of rides offered results in a reduction in waiting time $\left(\mathrm{T}_{\mathrm{A}}\right)$ and therefore in total travel time. Furthermore, because the supply schemes to compare have the same stops, the time $T_{I}$ necessary to reach the departure stop from the origin of the journey and to reach the destination from the arrival stop is the same in every scheme compared. Therefore, the term $T_{I}$ in (4) can be omitted. On the other hand, the weighted time of transfer is better represented by a straight line with an intercept $\neq 0$, as $\left(\mathrm{T}_{\mathrm{D}}+\mathrm{K}_{\mathrm{T}} \cdot \mathrm{T}_{\mathrm{T}}\right)$. In the latter, $\mathrm{T}_{\mathrm{D}}$ is the time penalty representative of the discomfort associated with a transfer operation requiring zero time. $\mathrm{T}_{\mathrm{D}}$ is different from zero since the transfer is perceived by users as an additional time even if it can be realized in no or negligible time.

Therefore, (4) turns in the following expression

$$
\mathrm{T}_{\mathrm{E}}=\mathrm{T}_{\mathrm{V}}+\mathrm{K}_{\mathrm{A}} \cdot \mathrm{T}_{\mathrm{A}}+\left(\mathrm{T}_{\mathrm{D}}+\mathrm{K}_{\mathrm{T}} \cdot \mathrm{T}_{\mathrm{T}}\right)
$$

Eq. (5) allows to evaluate an equivalent time to move from each origin to each destination. By this time, we measure the travel generalized cost only in terms of time spent. As the generalized cost is an inverse function of accessibility, the equivalent time evaluated by (5) is a measure of the accessibility and it is suitable to compare supply schemes that do not differ for monetary cost, comfort of the vehicle or the road risk, i.e. schemes of road public transit that have the same type of vehicles, the same routes and stops but differ for the number of transfers imposed and the number of rides supplied to users.

In truth, small differences in the risk of an accident may be found between the type A and type B schemes of supply also with the same overall mileage, due to a different daily mileage carried out by each driver and each vehicle, as well as due to other secondary factors, as noted by Porcu et al. (2020). However, these differences, besides to being minimal in the specific problem dealt with here, are not at all perceived by the user and therefore they do not fall within the generalized cost which, as well-known, is the cost perceived by the user.

Therefore, since $\mathrm{A}=\mathrm{K} / \mathrm{Cg}$ for (1) and having set $\mathrm{Cg}=\mathrm{Cg}\left(\mathrm{T}_{\mathrm{E}}\right)$, it follows that it is also

$$
\mathrm{A}=\mathrm{A}\left(\mathrm{T}_{\mathrm{E}}\right)
$$

where $T_{\mathrm{E}}$ is the equivalent time expressed by (5). In explicit terms

$$
\mathrm{A}=\mathrm{K} / \mathrm{T}_{\mathrm{E}}
$$

with $\mathrm{K}=$ constant $\neq 0$.

Since the accessibility has been defined by (7) as an inverse function of the equivalent travel time expressed by (5), it is possible to directly use the relation (5) as an inverse measure of the accessibility produced by the public transit service. To this end we must express $\mathrm{T}_{\mathrm{E}}$, and therefore its different parts, as function of the only characteristics that vary between the type A supply scheme (direct links) and the type B one (integrated links), that are:

- total travel time $(\mathrm{T})$,

- discomfort resulting from transfers (D), and

- number of rides available in the considered range of time (C).

Therefore, the equivalent travel time must be

$$
\mathrm{T}_{\mathrm{E}}=\mathrm{T}_{\mathrm{E}}(\mathrm{T}, \mathrm{D}, \mathrm{C})
$$


But, since $\mathrm{T}_{\mathrm{E}}=\mathrm{T}_{\mathrm{V}}+\mathrm{K}_{\mathrm{A}} \cdot \mathrm{T}_{\mathrm{A}}+\mathrm{T}_{\mathrm{D}}+\mathrm{K}_{\mathrm{T}} \cdot \mathrm{T}_{\mathrm{T}}$ (for 5), we have to express the variables $\mathrm{T}_{\mathrm{A}}$ and $\mathrm{T}_{\mathrm{T}}$ as a function of $\mathrm{D}$ and $\mathrm{C}$ and then calibrate the constants.

The equivalent travel time $T_{\mathrm{E}}$ used here measures the impedance connected to the trip and takes into account, in addition to the time spent running on the vehicle, also that necessary for any transfer as well as that lost at destination due to the arrival time of the outward ride and the departure time of the return ride which differ from those necessary to meet the purposes for which the journey is made. The time lost at destination is inversely proportional to the number of rides available in the considered time frame.

It is worth noting that we refer here to generic users, whose time needs are neither known nor similar. Otherwise, as known, with habitual users for work and study characterized by common and sufficiently defined time needs, direct links with time schedules calibrated to such needs respond well to the transport demand and they usually also produce high load factors. Hence, in these cases, the problem of replacing direct links with integrated ones generally does not arise.

We did not take into account the waiting time at departure of the outward journey because the intercity public transport service considered here is generally at scheduled time and not on frequency. In this case, the user reaches the bus stop, for the outward journey, only a few minutes before the time of the ride, and therefore, this waiting time is independent from the number of supplied rides. These limitations may be eliminated, with proper attention, without imposing any restrictions on the applicability of the proposed method.

Referring to intercity transport, in order to relate the number of rides to the idle or waiting time at destination $\left(\mathrm{T}_{\mathrm{A}}\right)$, at the arrival or restart, we considered a range in which the departure and return should be included (for example from 6:00 to 18:00) and it was divided into two equal parts (hence, two successive intervals from 6:00 to 12:00 and 12:00 to 18:00). As a result, the number of outward rides in the first semi-interval was considered in the hypothesis generally valid that the returning rides in the second range are the same and take place in the opposite direction.

The possible presence of a single transport ride in the semi-interval divides it into two parts and forces the user to wait an average time, for the return ride, equal to an half of one of the two parts of the semi-interval. In the range from 6:00 to 12:00 $(6 \mathrm{~h})$, the presence of just one ride implies a mean waiting time (in hours) of $0.5 \cdot 6 / 2$, with two rides of $0.5 \cdot 6 / 3$, with three rides of $0.5 \cdot 6 / 4$, and so on. Thus, in general, denoting $\mathrm{N}_{\mathrm{C}}$ as the number of outward rides in the semi-interval $\mathrm{I}_{\mathrm{N}}$, the theoretical waiting time $\mathrm{T}_{\mathrm{A}}$ that should be added to the travel time TV is

$$
\mathrm{T}_{\mathrm{A}}=0.5 \cdot \frac{I_{N}}{\left(N_{C}+1\right)}
$$

with $\mathrm{I}_{\mathrm{N}}=6 \mathrm{~h}$ (or $360 \mathrm{~min}$, outward interval, equal to half of the total daily range, assumed to be approximately $12 \mathrm{~h}$ considering the type of mobility) and $\mathrm{N}_{\mathrm{C}}=$ number of outward rides in the $\mathrm{I}_{\mathrm{N}}$ range.

The equivalent travel time $\mathrm{T}_{\mathrm{E}}$ defined by (6) can be expressed as:

$$
\mathrm{T}_{\mathrm{E}}=\mathrm{T}_{\mathrm{V}}+\mathrm{K}_{\mathrm{A}} \cdot 0.5 \cdot \frac{I_{N}}{\left(N_{C}+1\right)}+\mathrm{N}_{\mathrm{T}} \cdot\left(\mathrm{T}_{\mathrm{D}}+\mathrm{K}_{\mathrm{T}} \cdot \mathrm{T}_{\mathrm{T}}\right)
$$

where $T_{V}=$ real travel time from the origin to destination, (that is the time spent inside a vehicle) net of the transfer time; operation;

$\mathrm{T}_{\mathrm{D}}=$ time penalty representative of the discomfort associated with the transfer

$$
\mathrm{N}_{\mathrm{T}}=\text { number of transfers necessary for the journey; }
$$


$\mathrm{T}_{\mathrm{T}}=$ overall average time to make a transfer;

$\mathrm{K}_{\mathrm{A}}$ and $\mathrm{K}_{\mathrm{T}}=$ calibration coefficients representative of the weight (compared to the travel time on the vehicle $\mathrm{T}_{\mathrm{V}}=1.0$ ) of the $\mathrm{T}_{\mathrm{A}}$ and $\mathrm{T}_{\mathrm{T}}$ times, i.e. the user's willingness to exchange a certain amount of these times with an unit of $\mathrm{T}_{\mathrm{V}}$.

It should be noted that increasing the number of rides at the denominator in (10), $\mathrm{T}_{\mathrm{A}}$ describes a decreasing curve having a nonlinear trend and upward concavity. This is consistent with what can be observed in reality in which the contribution, in terms of accessibility, provided by each additional ride with the same travel time, decreases as the number of available rides increases.

In Eq. (10), the term related to transfer is composed of two addenda: the first concerns the burden representing the discomfort resulting from the transfer while the second takes into account the time, appropriately weighted, used in this operation. The trend of the representative function is linear with the intercept different from zero and equal to $T_{D}$.

The application of (10) requires the calibration of the coefficients $\mathrm{K}_{\mathrm{A}}$ and $\mathrm{K}_{\mathrm{T}}$ and the discomfort time $\mathrm{T}_{\mathrm{D}}$ and also an $\mathrm{I}_{\mathrm{N}}$ interval consistent with the analysed context. The calibration of the $\mathrm{K}_{\mathrm{A}}$ and $\mathrm{K}_{\mathrm{T}}$ coefficients and of the transfer penalty $\mathrm{T}_{\mathrm{D}}$ should be performed by surveys through submitting questionnaires, with revealed and stated preferences, to users. However, in the first instance, values drawn from literature, calibrated on equivalent fields and services, may be taken as bases. Indeed, the searched $\mathrm{K}_{\mathrm{A}}$ and $\mathrm{K}_{\mathrm{T}}$ values are the importance attributed by users to $\mathrm{T}_{\mathrm{A}}$ and $\mathrm{T}_{\mathrm{T}}$ accessory time with respect to the time spent on board $\mathrm{T}_{\mathrm{V}}$. Thus, we used international studies drawing these values mainly in the building of quality and utility models for public transit.

As already known, the waiting time at the bus stop and that spent during a possible transfer have a different value for the user than the time on the vehicle. Therefore, the $\mathrm{K}_{\mathrm{A}}$ and $\mathrm{K}_{\mathrm{T}}$ coefficients assume values that are certainly more than one unit. The $\mathrm{K}_{\mathrm{A}}$ coefficient is the equivalent or the trade-off value ascribed by users between a unit of waiting time $\mathrm{T}_{\mathrm{A}}$ and a unit of travel time spent on board $\mathrm{T}_{\mathrm{V}}$. The $\mathrm{K}_{\mathrm{T}}$ coefficient represents the equivalent or the trade-off value on a unit of time spent in transfer $\mathrm{T}_{\mathrm{T}}$ and a unit of time on board $\mathrm{T}_{\mathrm{V}}$. Therefore, $\mathrm{K}_{\mathrm{A}}$ and $\mathrm{K}_{\mathrm{T}}$ are multipliers that are proportional to the weight associated by the user, respectively to the waiting and transfer time, compared to the time spent on board.

Table 1 refers the values determined in some studies concerning the analysis of the assessment of the time perception by users of public transport:

\begin{tabular}{lc}
\multicolumn{1}{c}{ Reference } & Wait time/Travel time \\
Parsons Brinckerhoff Quade and Douglas Inc. (1998) & 2.58 \\
Barton-Ashman Associates (1993) & 2.13 \\
Parsons Brinckerhoff Quade and Douglas Inc. (1999) & 3.41 \\
Wardman (2001a, 2001b) & 1.47 \\
\multicolumn{1}{c}{ Average value } & $\mathbf{2 . 4 0}$
\end{tabular}

Table 1 - Values of waiting time multiplicative coefficient, considering 1.0 the time on board, taken from Iseki and Taylor (2009)

The values set in the main studies analysed by Fan et al. (2016), which can be used for our purpose, are summarized in table 2: 


\begin{tabular}{|cc}
\multicolumn{1}{c}{ Reference } & Ratio \\
\hline Wardman (1998a) & $1.2 \div 1.7$ \\
\hline Wallis et al. (2013) & 1.3 \\
\hline Wardman (2013) & $1.5 \div 1.9$ \\
\hline Abrantes and Wardman (2011) & $1.4 \div 2.3$ \\
\hline Horowitz (1981) & $1.9 \div 2.3$ \\
\hline Wardman (2004) & 2.5 \\
\hline Average value & $\mathbf{1 . 8 2}$
\end{tabular}

Table 2 - Ratio between waiting time and TV summarized by Fan et al. (2016)

Finally, considering all the results of the analysed studies, we decided to assume a value of the waiting time coefficient $\mathrm{K}_{\mathrm{A}}$ equal to 2.11 , that is the average value between the ratios shown in tables 1 and 2 . This outcome is close to 2 , which is the rough weight generally adopted for ratio between waiting and travel time in the technical practice of modelling the modal split.

To evaluate $\mathrm{T}_{\mathrm{T}}$ and $\mathrm{K}_{\mathrm{T}}$ (in table 3) we refer to the work of Wardman et al. (2001).

$\begin{array}{lcc}\text { Penalty at transfer between buses (Transfer discomfort as time) } & \text { Minutes } & \text { Ratio } \\ \text { Penalty at transfer between buses (Transfer discomfort as time) at guaranteed } & 4.5 & - \\ \text { connection } & 3.6 & - \\ \text { Time at transfer between buses; walk time to travel time ratio } & - & 1.6 \\ \text { Time at transfer between buses; wait time to travel time ratio } & - & 1.2\end{array}$

Table 3 - Transfer discomfort as time (transfer penalty) in minutes and weight of waiting and walking time at vehicle interchange, compared to travel time (Wardman et al., 2001)

Therefore, the values of 3.6 min and 1.4 will be used in the model (mean between walking and waiting time values) for $\mathrm{T}_{\mathrm{D}}$ and $\mathrm{K}_{\mathrm{T}}$, respectively.

The transfer operation takes for granted a minimum time necessary to be able to get off one bus and get on the other. We assumed this time as $5 \mathrm{~min}$ as we took for granted a good synchronization of coinciding rides and in any case a guaranteed connection.

In summary, the calibration values for the model constants (11) are

$$
\mathrm{K}_{\mathrm{A}}=2.11 \quad \mathrm{~K}_{\mathrm{T}}=1.4 \quad \mathrm{~T}_{\mathrm{D}}=3.6 \mathrm{~min}
$$

Therefore, the calibrated model is

$$
\begin{aligned}
& \left.\mathrm{T}_{\mathrm{E}}=\mathrm{T}_{\mathrm{V}}+2.11 \cdot 0.5 \cdot \frac{I_{N}}{\left(N_{C}+1\right)}+\mathrm{N}_{\mathrm{T}} \cdot\left(3.6+1.4 \cdot \mathrm{T}_{\mathrm{T}}\right)\right] \\
& \left.\mathrm{T}_{\mathrm{E}}=\mathrm{T}_{\mathrm{V}}+1.055 \cdot \frac{I_{N}}{\left(N_{C}+1\right)}+\mathrm{N}_{\mathrm{T}} \cdot\left(3.6+1.4 \cdot \mathrm{T}_{\mathrm{T}}\right)\right]
\end{aligned}
$$

with the meaning as previously described and with all times $\left(\mathrm{T}_{\mathrm{E}}, \mathrm{T}_{\mathrm{V}}, \mathrm{T}_{\mathrm{T}}\right)$ in minutes.

\section{Analysis and results}

The present accessibility model has been applied to a portion of the intercity local public transport service network of the Matera Province, in Southern Italy (Figure 4). The current transport supply consists of all direct links between the served municipalities, which are carried out without transfers, and it has a configuration similar to the previously discussed scheme A. The service has currently reached a very low average load factor and therefore, it requires a rationalization, while still ensuring the existing connections.

In this context, we decided to redesign a part of the current network of transport services by replacing most of the direct links with integrated ones. This is realized by using connection lines at certain transfer points from departure to arrival. Therefore, the new service network is ascribable to the previously discussed scheme B. 


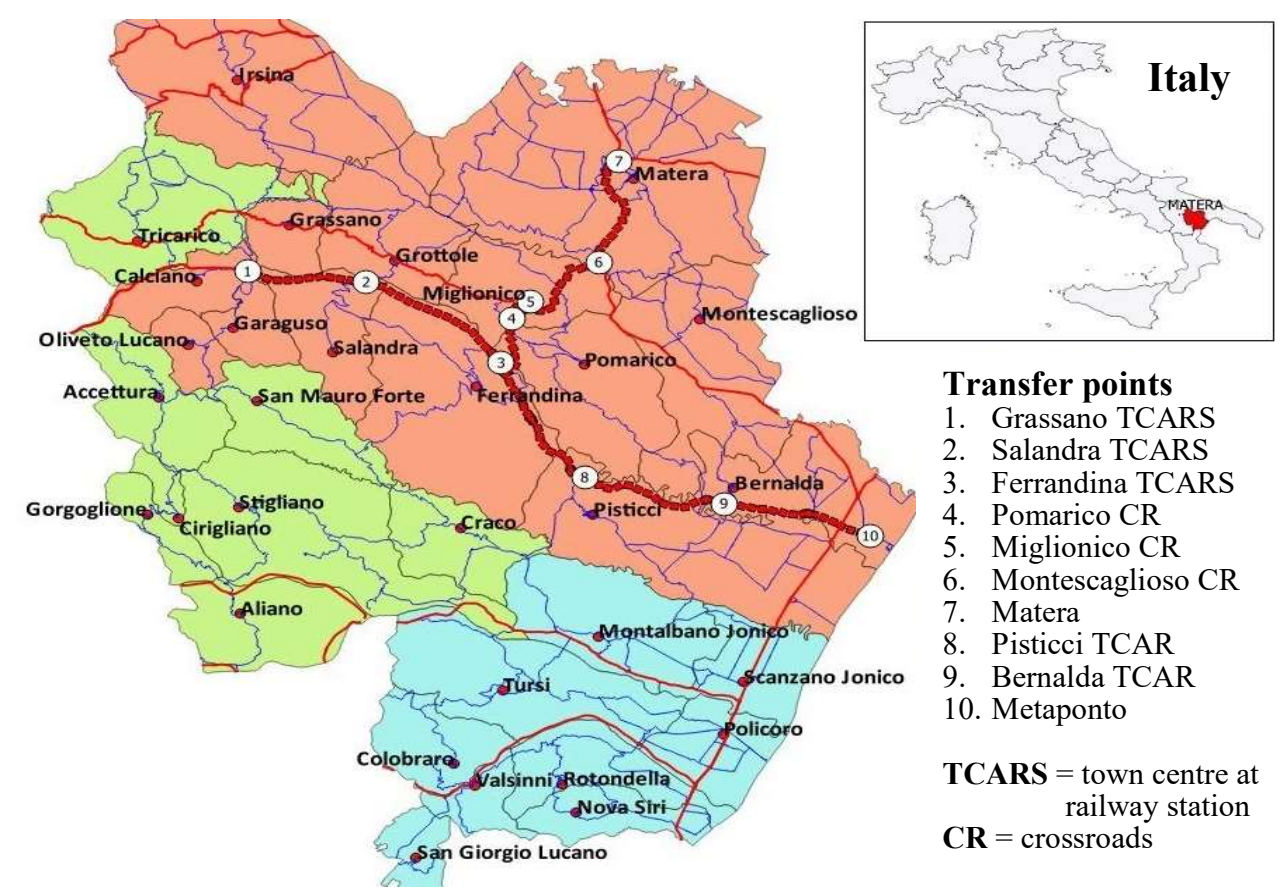

Figure 4 - Area of study: province of Matera (Italy) with transfer points of the projected network ${ }^{1}$

Then, through the accessibility model, the current supply pattern and that of the project have been compared. They, while carrying out roughly the same overall mileage, differ by type because the first has all direct links and less number of rides, whereas the second has mostly integrated links and a greater number of rides. In particular, we calculated the average equivalent time $\mathrm{T}_{\mathrm{E}}$ for the current scheme, and then, repeatedly for the project, increasing the number of supplied rides each time, starting from the number of the rides on present scheme, and consequently detect a decrease in $\mathrm{T}_{\mathrm{E}}$, until it reached a value close to that of the current scheme. Thus, we obtained an integrated-link supply network, which, as owes an additional number of routes compared to the current network, compensates for the discomfort resulting from the transfers and ensures the same accessibility evaluated through the average equivalent time $\mathrm{T}_{\mathrm{E}}$. The result showed that the number of additional required rides restores the accessibility produced by the integrated scheme (penalized by transfers) to a value equal or very close to that of the direct link pattern.

The redesigned supply is structured with two valley transport lines having adequate capacity suitable for the low demand. These run along S.S. 407 (part of the European Route E 847) and S.S. 7, from Ferrandina rail station (TCARS) to Matera and vice versa, and along S.S. 7 and S.S. 407 from Matera to Metaponto and vice versa, respectively. On these routes, transfer points were located (highlighted in Figure 4). The transfer between the valley lines and those of the connections to the hill centres will take place at these points.

\footnotetext{
1 The areas with different colours are representative of the three traffic sub-basin identified by the Basin Plan of Public Transport of Matera Province and the application developed here concerned only the sub-basin of Matera (the area in red/orange color).

The red thick routes represent the main roads along which the trunk line of the feeder-trunk scheme run. The numbers identify the position of the transfer points named in the table shown in the figure.
} 
In line with the schematization adopted in the construction of the model, we divided the interval in which the transport services are supplied (6:00-18:00) in two semiintervals (6:00-12:00 and 12:00-18:00), during which all outward and return rides, respectively, are carried out. Therefore, the redesign of services concerned only the first half of the interval, because in the second, the same rides in the opposite direction take place.

By processing the timetables, the mileages and travel times of each line have been calculated and then, according to the method mentioned previously, the proposed model has been applied.

Obviously, the number of transfers is always zero in the existing services, because the current supply is configured in according with the scheme A (direct links). Concerning the project transport supply ascribable to scheme B (integrated links), the time required for one transfer has been set as $5 \mathrm{~min}$. Actually, it is a precaution because the transfer of a few passengers, mostly devoid of baggage, from one bus to another arriving almost simultaneously requires less time.

The number of the transit rides on valley line and of those connecting the hilly centres with the transfer points have been calculated based on the rides that has been added in order to overcome the disutility owing to the transfer requested by most of the links. We emphasize that to ensure a complete connection, the link of each centre to a close transfer point must provide a forward and return ride (to and from the centre); consequently, the number of rides is doubled in the mileage evaluation. The valley lines are set in such a way that a ride starts from each of the opposite terminal, and the number of rides in these lines has been doubled for the proper mileage counting, albeit for a different reason.

It should be noted that the equivalent time $\mathrm{T}_{\mathrm{E}}$ resulting from the application of the model to both the project scheme and the current one is expected to achieve the same value as the target. Indeed, the application proposed is finalized to quantify the number of rides that should be added in the integrated link pattern to compensate for the time that has been wasted and the discomfort imposed on users by the transfer. Therefore, the application method, as already mentioned, implies consecutive elaborations using as input the number of rides starting from that of the current supply scheme as input in order to reduce the equivalent time $T_{E}$ in the project supply pattern until it reaches the value of the current scheme. Unfortunately, the necessary approximation (in this case, for excess) of the number of rides to the unit on each line, does not allow the $\mathrm{T}_{\mathrm{E}}$ of the designed scheme to achieve exactly the same value of the current pattern (specifically, 16 min less, equivalent to $-9.3 \%$ ).

The results reported in Table 4 show that, for the examined situation, the equivalent time $\mathrm{T}_{\mathrm{E}}$ of the projected scheme (integrated links) almost equal the value reached in the current scheme (direct links), thus the number of rides in the 6:00-12:00 time slot needs to increase by $39.0 \%$, from the current 82 (the only non-dedicated rides considered in the redesign) to the provided 114. Furthermore, the increase in the number of rides from the current situation allows a reduction of $28 \min (-23 \%)$ on the weighted waiting time at the destination $\left(\mathrm{K}_{\mathrm{A}} \cdot \mathrm{T}_{\mathrm{A}}\right)$. 
$\mathbf{N}_{\mathbf{C}}$ : Number of rides in the interval 6:00-12:00

$\mathbf{N}_{\mathbf{T}}$ : Number of transfers (1 connection/route)

$\left(\mathbf{K}_{\mathbf{A}} \cdot \mathbf{T}_{\mathbf{A}}\right)$ [min]: Average of weighted waiting time

$\left(\mathbf{T}_{\mathbf{D}}+\mathbf{K}_{\mathbf{T}} \cdot \mathbf{T}_{\mathbf{T}}\right)[\mathrm{min}$.$] : Average of weighted transfer time$

$\mathbf{T}_{\mathbf{E}}$ [min]: Average equivalent time

$\begin{array}{ccccc}\text { Current [1] } & \text { Design [2] } & \boldsymbol{\Delta}[\mathbf{2 - 1 ]} & \boldsymbol{\Delta} \%[\mathbf{2}-1] \\ 82 & 114 & 32 & 39 \% \\ 0 & 32 & 32 & --- \\ 119 & 91 & -28 & -23 \% \\ 0 & 8 & 8 & --- \\ 185 & 169 & -16 & -9 \%\end{array}$

Legend: [1] Current transport supply (scheme A); [2] Transport supply redesigned according to scheme B, with number of rides greater than the current supply and suitable to approximately make the equivalent time TE of the designed supply equal to current one.

Table 4 - Public transit alternatives compared by the built model

The higher number of rides in the integrated supply scheme does not necessarily imply a greater overall mileage than the existing one with direct links, as the first type of scheme, being more efficient, is generally able to guarantee a greater number of rides with the same mileages. Indeed, in the examined case, despite the increase in the number of rides from 82 to 114, a slight mileage saving of only over $4 \%$ resulted from the project scheme.

\section{Conclusions}

The present work proposes a model for evaluating, by the equivalent travel time, the accessibility produced by a public transit service.

The developed assessment tool fills an important gap in the scientific literature of the sector. Indeed, the latter rarely dealt with accessibility given by public transport to the served area and in any case lacks a model suitable to evaluate, in this respect, supply schemes that differ mainly in the level of integration of the lines between them and the number of offered rides. This tool is particularly useful in the design of the public transport service to compare different supply schemes in terms of produced accessibility.

The model built was finally applied to a real case to test its functioning and highlight the advantages and limitations deriving from the supply schemes with a high level of lines integration.

The number of transfers from one vehicle to another while travelling and the number of rides supplied over a defined period play an important role in the accessibility produced by a public transit service. In fact, transfers cause a reduction in comfort and an increase in travel time, and consequently, an increase in the generalized cost for users. The increase in the number of supplied rides brings the time of service closer to the needs of the users and, therefore, reduces the time lost at a destination and the time interval between departure from the origin and return to the same point (total travel time in round trip).

It is also evident that the number of transfers needed and the number of rides supplied are related service parameters. In fact, the integrated public transport supply scheme, i.e. the one that makes possible each link by forcing users to move from one line to another allows, with respect to the direct link scheme, to realize the same connections with a total mileage saving that can be reused to increase the number of supplied rides. Thus, it can be concluded that there is a need to compare, in the design stage, the effectiveness in terms of accessibility given by different public transit supply schemes that offer the same mileage but differ on the number of required transfers and of supplied rides. Therefore, the accessibility model presented here has been formulated to take into account the inconvenience caused by possible transfers from one vehicle to another and the advantage produced by the greater number of available rides.

This model is a useful support tool to design and/or optimize local public transport services. Indeed, when we pass from a low integration scheme to an higher integration 
one, it also allows us to evaluate the minimum number of rides that should be added to the original supply scheme, to compensate, in terms of the equivalent time $\mathrm{T}_{\mathrm{E}}$, the wasted time and discomfort for users coming from a greater number of transfers which are a consequence of the replacement of a number of direct links with integrated ones. Realizing this compensation between the number of additional transfers and additional rides, the user will perceive the service supplied with integrated connections (concerning the accessibility measured through equivalent time $\mathrm{T}_{\mathrm{E}}$ ) as equivalent to that with direct links. A possible increase (or decrease) in the number of rides higher than strictly necessary to compensate for the larger number of transfers will result in a greater (or lower) produced accessibility and service attractiveness.

The proposed model is generally valid, but the calibration carried out under the precise assumptions limits the range of applicability. Its employment in different areas requires a new calibration of the constants. Therefore, the developed model is applicable for evaluating the accessibility (expressed through the equivalent travel time $\mathrm{T}_{\mathrm{E}}$ herein defined) produced by public transport services by road or rail or in combination, which realize intercity connections in regional or sub-regional areas with travel times of the order of $20 \div 120 \mathrm{~min}$.

The time required for transfers should be minimized and this operation should make easier by equipping the transfer points in a suitable manner. Finally, it is evident that the supply patterns with a predominance of integrated links (and therefore tending to feedertrunk scheme) are easily applicable to widespread demand areas, if we have free capacity available on the main lines, receiving users from more connecting lines. With a more concentrated demand, such capacity availability should be properly verified. On the other hand, feeder-trunk supply schemes are less suitable to serve a concentrated demand in terms of time and origin/destination, such as that generated by a commuting mobility for work or study towards well-defined destinations.

The model proposed here can be improved in terms of reliability through a new calibration of the constants. This operation must make use of data collected from interviews administered to a wide audience of users of different types. In this way it would be possible to determine values for the weights of the components of the equivalent travel time suitable for both general users (trips for undefined reasons) and specific users (trips for study, work, purchases, etc.) and for different travel distances (in urban, suburban and regional areas) as well as for different frequency of trips (daily, weekly or occasional commuting).

An important aspect to consider when comparing feeder-trunk and direct-link supply schemes concerns the running cost per kilometer. In fact, while in this work we assumed that the cost of a transit service based on different supply schemes depends only on the overall mileage, it is known instead that services with shorter lines covered by a greater number of rides that characterize the feeder-trunk schemes have a lower running cost per kilometer than those organized on the basis of a direct-link scheme. This is a consequence of a greater use, in the first type of scheme compared to the second one, of drivers (and also rolling stock) who, having less downtime during the work shift, can drive longer hours. Unfortunately, the formulas for calculating the standard cost imposed in Italy by MIT (2018) do not allow to detect these differences in cost per kilometer because they do not take into account, among other things, the supply density (produced mileage / length of the lines). A step in the direction of overcoming the ministerial approach to determining the standard cost was taken by Petruccelli and Racina (2019) who developed a model to estimate the number of drivers required for a given road public transit service. Once the 
number of drivers is known, it is possible to calculate the standard cost, thus indirectly taking into account the service density from which, as is well known, the number of drivers depends.

Obviously, the choice between direct-link and feeder-trunk supply schemes must take into account, although with a significantly lower weight than the territorial accessibility produced, also other aspects, such as network reliability, the possible effects on demand and the manager's point of view.

As far as reliability is concerned, with reference to public road transport, it should be considered that possible service stops may be due to interruptions in the infrastructure network or vehicle breakdowns. In the first case, the reliability of the two schemes is identical since the service is carried out on the same roads. In the second case, the shorter lines made in feeder-trunk schemes are somehow to prefer because they allow a shorter lap time for the rides and therefore they ease to replace an out of use vehicle.

The objective of increasing the demand for public transit would favour at a first glance for the feeder-trunk scheme which can offer to the users a greater number of rides for the same overall service mileage and therefore be more attractive. However, if the two schemes provide the same accessibility to the territory and therefore the same equivalent travel time TE, as defined by (4) and (5), their attractiveness is identical because the advantage resulting from the greater number of supplied rides is exactly compensated from the discomfort of transferring from one vehicle to another.

The manager's point of view is closely linked to the real operating cost. A service that makes a greater number of trips on shorter lines certainly presents a better use of drivers and vehicles that are able to travel more kilometers during each work shift, due to the reduction of downtime between two successive outward or outward and return rides (see in this regard the work of Petruccelli and Racina, 2019). The shorter lines that characterize the feeder-trunk scheme allow, among other things, a better adjustment of the supply to the demand in terms of number of rides and vehicle capacity and consequently a higher load-factor and accordingly, in principle, a greater efficiency. Therefore, the feeder-trunk service generally corresponds to a lower running cost per kilometer than that of the directlink, even if the cost of creating and managing the interchange points must be added to the first. However, as already mentioned previously in this section, the formulas for calculating the standard cost, imposed by MIT (2018), do not count the number of supplied rides (supply density) affecting the average mileage produced by each driver, and therefore they gives the same cost per kilometer for the two schemes. Thus the savings achievable with the feeder-trunk scheme translates into a greater profit for the manager. If, on the other hand, the density of the supply was also taken into account in the calculation of the standard cost, the feeder scheme would correspond to a lower cost per kilometer with a saving for the public authority and indifference for the manager.

\section{References}

Abrantes, P., Wardman, M. (2011). Meta-analysis of U. K. values of time: an update. Transportation Research, Part A: Policy Practice, 45 (1), 1-17.

Barton-Ashman Associates (1993) Estimation, Calibration, and Validation of the Houston Mode Choice Model. Technical Report. Prepared for the Metropolitan Transit Authority of Harris County, Houston, TX.

Cattan, N. (1992). Air and Rail Accessibilities and Attractivities on European Metropolis, 6th World Conference on Transport Research, Lyon, June 29 - July 3 td. 
Chowdhury, S.; Ceder, A. (2013). Definition of planned and unplanned transfer of public transport service and user decisions to use routes with transfers. Journal of Public Transportation, 16.2: 1.

Chowdhury, S.; Hadas, Y.; Gonzalez, V.A; Schot, B. (2018). Public transport users' and policy makers' perceptions of integrated public transport systems. Transport Policy, 61: 75-83.

Dalvi, M; Martin, K. M. (1976). The measurement of accessibility: some preliminary results, Transportation, 5, pp. 17-42.

Douglas, N. J., Jones, M. (2013). Estimating transfer penalties and standardised income values of time by stated preference survey. In Australian Transport Research Forum.

Fan, Y., Guthrie, A., Levinson, D. (2016). Waiting time perceptions at transit stops and stations: Effects of basic amenities, gender, and security. Transportation Research Part A: Policy and Practice, 88, 251-264.

Gschwender, A.; Jara-Díaz, S.; Bravo, C. (2016). Feeder-trunk or direct lines? Economies of density, transfer costs and transit structure in an urban context. Transportation Research, Part A: Policy and Practice, 88, 209-222.

Guihaire, V.; Hao, J-K. (2008). Transit network design and scheduling: A global review. Transportation Research, Part A: Policy and Practice, 1251-1273.

Horowitz, A. (1981). Subjective value of time in bus transit travel. Transportation 10, $149-164$.

Iseki, H; Taylor, B. D. (2009). Not all transfers are created equal: Towards a framework relating transfer connectivity to travel behaviour. Transport Reviews, 29.6: 777-800.

Jara-Díaz, S., R.; Gschwender, A.; Ortega, M. (2012). Is public transport based on transfers optimal? A theoretical investigation. Transportation Research Part B: Methodological, 46, 808-816.

Kindlmann, P.; Burel, F. (2008). Connectivity measures: a review. Landscape Ecology 8 (23), Pp. 879-890.

Mishraa, S.; Welch, T. F.; Jha, M. K. (2012). Performance indicators for public transit connectivity in multi-modal transportation networks, Transportation Research Part A: Policy and Practice, 7 (46), pp. 1066-1085.

MIT - Italian Ministry of Infrastructures and Transport (2018). Ministerial Decree 28-032018 n.157 - "Definizione dei costi standard dei servizi di trasporto pubblico locale e regionale e dei criteri di aggiornamento e applicazione".

Murray, A. T., Wu, X. (2003). Accessibility tradeoffs in public transit planning. Journal of Geographical Systems, 5.1, 93-107.

Parsons Brinckerhoff Quade and Douglas Inc. (1998) Cleveland Regional Travel Demand Forecasting Model Documentation Report. Prepared for the Greater Cleveland Regional Transit Authority and the Northeast Ohio Areawide Coordinating Agency.

Parsons Brinckerhoff Quade and Douglas Inc. (1999) Travel Demand Model Development Methodology Report. North Illinois Regional Commuter Railroad Corporation (METRA).

Petruccelli, U.; Racina, A. (2019). Stima del numero di conducenti come strumento di efficientamento dei servizi di trasporto pubblico. Assessment of the drivers number as a tool for improving efficiency of public transport services. Ingegneria Ferroviaria, 4; 295-315.

Porcu, F.; Olivo, A.; Maternini, G.; Barabino, B. (2020). Evaluating bus accident risks in public transport. Transportation Research Procedia, 45, 443-450.

Sivakumaran, K.; Li, Y.; Cassidy, M. J.; Madanat, S. (2012). Cost-saving properties of schedule coordination in a simple trunk-and-feeder transit system. Transportation Research Part A: Policy and Practice, 46, 131-139.

Vasconcelos, S., Farias, T. L. (2012). Evaluation of urban accessibility indicators based on internal and external environmental costs. Transportation Research Part D: Transport and Environment, 17.6, 433-441. 
Wallis, I., Lawrence, A., Douglas, N. (2013). Economic Appraisal of Public Transport Service Enhancement. Research Report 533, New Zealand Transport Agency.

Wardman, M. (1998a). A Review of British Evidence on the Valuations of Time and Service Quality. Department of the Environment, Transport and the Regions, Leeds.

Quality. Working Paper 525, Institute for Transport Studies, University of Leeds

Wardman, M.; Hine, J.; Stradling, S. (2001). Interchange and Travel Choice, Vol. 1. Edinburgh: Scottish Executive Central Research Unit. Edinburgh.

Wardman, M. (2001a). Public Transport Values of Time. Working Paper 564, Leeds: Institute of Transport Studies, University of Leeds.

Wardman, M. (2001b). A review of British evidence on time and service quality valuations, Transportation Research Part E: Logistics and Transportation Review, 37E (2-3), pp. 107-128.

Wardman, M. (2004). Public transport values of time. Transport Policy, 11 (4), 363-377.

Wardman, M. (2013). Value of time multipliers: a review and meta-analysis of Europeanwide evidence. In: TRB 92nd Annual Meeting Compendium of Papers. Paper presented at the 92nd Annual Meeting of the Transportation Research Board, Washington, DC, 13-17 January, pp. 1-18. 